\title{
REMOTELY SENSED DATA FUSION IN MODERN AGE ARCHAEOLOGY AND MILITARY HISTORICAL RECONSTRUCTION
}

\author{
A. Juhász ${ }^{\text {** }}$ H. Neuberger ${ }^{\mathrm{a}}$ \\ ${ }^{a}$ BME, Faculty of Civil Engineering, 1111 Budapest, Müegyetem rkp. 3, Hungary - (juhasz.attila, \\ neuberger.hajnalka)@epito.bme.hu
}

Technical Commission V, WG V/2

KEY WORDS: LiDAR, remote sensing, GIS, archaeology, military historical reconstruction

\begin{abstract}
:
LiDAR technology has become one of the major remote sensing methods in the last few years. There are several areas, where the scanned 3D point clouds can be used very efficiently. In our study we review the potential applications of LiDAR data in military historical reconstruction. Obviously, the base of this kind of investigation must be the archive data, but it is an interesting challenge to integrate a cutting edge method into such tasks. The LiDAR technology can be very useful, especially in vegetation covered areas, where the conventional remote sensing technologies are mostly inefficient. We review two typical sample projects where we integrated LiDAR data in military historical GIS reconstruction. Finally, we summarize, how laser scanned data can support the different parts of reconstruction work and define the technological steps of LiDAR data processing.
\end{abstract}

\section{INTRODUCTION}

\subsection{Potential LiDAR based archaeological and military applications}

As it is well known, LiDAR is an active remote sensing technology. There are terrestrial and airborne laser scanning solutions. In the airborne case the scanner, mounted on some kind of mobile platform (airplane, helicopter), emits a laser beam and measures the time it takes to return to its source. To calculate coordinates from the raw telemetries, we also need the position and the orientation of the laser pulse: the accurate coordinates of the sensor and the angle of the emitted pulse. Usually GNSS and INS systems are applied to determine these data. In practice, the laser beam sweeps the surface of the ground across the flying track (Lovas et al., 2012). According to the basic characteristics of the laser beam (monochromatic, coherent, small divergence, polarized, concentrated energy), it reaches the ground surface as an ellipse (in practice with about $25-40 \mathrm{~cm}$ major axis) called the footprint, and then reflects from this point. A single laser beam can be reflected from numerous and various levels (ground level, understory level, crown level), this is called multiple returns. The early systems could record only one return, and then the first and last ones. Nowadays, it is possible to record more discrete returns (even 4-6) and, besides, the full waveform of the beam can also be detected by some systems. Accuracy is another important characteristic that have to be discussed. Basically, the overall accuracy depends on the accuracy of the components (laser rangefinder, GNSS, INS) and the calibration of the sensor and the navigation system. Omitting the details, we can declare that in practice the accuracy of this measurement is about $10-20 \mathrm{~cm}$ vertically and about 20-30 cm horizontally.

Thanks to these characteristics listed above, there are various applications of the LiDAR data. The point clouds are useful in different technical and human disciplines: forestry management and planning, flood modelling, mapping and cartography, coastline management, transport planning, archaeology, etc. (Vosselmann et al., 2010). Also there are several published results known in our research area: the reconstruction of archaeological and military historical defence objects. However, these projects contain laser scanned data application mostly in the classic archaeological periods, like the LiDAR supported research in Angkor, where new city parts were mapped (Evans et al., 2013) or several European examples of detecting burial places (Draganits E. et al., 2015), (John J. et al., 2012). In the last few years such researches were carried out also in Hungary. Our department is taking part in a cooperation, where we can apply LiDAR data in different fields of scientific researches. The reconstruction of archaeological and military historical objects in GIS is one of these fields. Besides, our goal is to integrate the wider spectrum of remotely sensed data in these GIS reconstructions, according to our possibilities. In this paper we review our research topic and our results. Despite our recent research focuses on modern age, we would like to discuss an example from an earlier historical period. In this project a field fortress and burial places were detected (Figure 1.) and mapped in Baranya county, on Jakab-mountain near Pécs (Gáti Cs., 2014), (Bertók G. et al, 2014).

Based on these results, according to the size of the identified burial places and the existing vegetation cover, the LiDAR technology seems appropriate to detect modern age archaeological and military historical objects (mostly trenches and fieldworks). There are only a few international examples can be found in connection with this period and topic. The detection of World War I. trenches near Kemmelberg (Belgium) is one of the typical investigations (Stal C. et al, 2010). The correct and objective reconstruction of the military defence objects has a great influence on military historical researches, and LiDAR data are usable in such areas, where other traditional remote sensing technologies are not.

\footnotetext{
* Corresponding author
} 


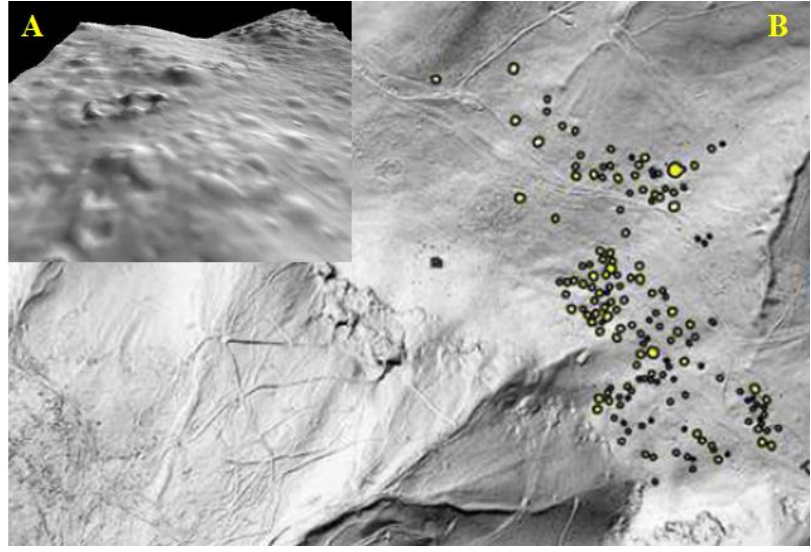

Figure 1. Burial place detection in 3D (A) and 2D (B) view

\section{$1.220^{\text {th }}$ century's Hungarian military objects}

In this section we briefly summarize the military historical events, locations and the typical military defense objects of the $20^{\text {th }}$ century in Hungary. There are no existing significant military objects (fortress or fortress parts) connected to the World War I. in Hungary. However, there are some infrastructural and serving facilities throughout the country (Budapest, Komárom, Mosonmagyaróvár). These facilities are mostly well known and mapped. LiDAR scanning of these buildings can be used as reference data to locate and identify such objects in the investigation of new areas. Additionally, LiDAR measurements can be controlled and validated by field measurements.

As opposed to World War I, a lot of important events of World War II happened in the country. The objects that formed defensive fortifications (lines) built in this period are the potential targets of our research. These defensive lines were spanned across the whole country from the north eastern region to the south western direction (Árpád-, Karola-, Attila-, Margitline). The most important parts of these defence systems were the anti-tank trenches, the infantry trench systems and the various placements (flack, artillery). Based on the size of these defence objects we can suppose that current measurements are also able to capture the signs of the larger parts of the defensive lines. The proper sizes of the anti-tank trenches are 8-10 meters in width and 4-6 meters in depth, so there is a great chance to locate the remains despite the several decades of intensive agricultural activities on the concerned areas. Unfortunately, most infantry trenches have already been disappeared from these agricultural areas, but there were several cases when the trenches were built next to the forests or parallel with roads; some of these areas are still nearly untouched. In these cases the trenches are usually covered by dense vegetation (grass, bushes, trees), so it seems reasonable to apply LiDAR survey and the most common process, the digital elevation model generation through vegetation removal. The remains of the trenches are 10.1 meter deep, so it can be declared that the trench point should be well separated from other ground points in the point cloud. Beside the World War II defensive lines, the South Defensive System (SDS) has to be mentioned, which was built in the early 1950's. It was located close to the former Yugoslavian border and was constructed in almost the same way as the earlier defensive lines, mentioned above. The SDS consisted of both field- and permanent-fortification parts. In addition, we have to note that there have been only a few airborne LiDAR measurements carried out in Hungary until now. Unfortunately none of these measurements were accomplished to reconstruct military defensive objects from the $20^{\text {th }}$ century. However, there are some point clouds created by museums and national parks, which include areas where potential defensive objects can be found. In these cases there is a possibility to locate these trenches or placements and to validate the known information based on laser scanned data.

\section{LIDAR DATA IN MODERN AGE ARCHAEOLOGICAL GIS RECONSTRUCTION}

\subsection{Detecting archaeological and military historical objects}

In this section we review the point cloud processing, interpretation and visualization techniques, which can effectively support military historical object reconstruction. First, we have to mention, that there is a known reconstruction methodology based on traditional data sources (archive maps and aerial photographs, field measurements, personal reminiscences) that can be applied successfully in $20^{\text {th }}$ century's military object reconstruction. The integration of airborne laser data into this conventional process is a significant step forward, considering the result's quality. In addition there is a unique potential in this technology to detect military objects especially in vegetation covered areas, in contrast with any other remote sensing methods (Juhász A., 2007). As mentioned previously, the earlier types of the LiDAR sensors could detect just a single reflected signal. The main analysis and interpretation processes can be carried out on this kind of (containing only first pulse reflections) point cloud, too. The first and probably the most important process is the classification of the point cloud. The primary goal of this step is to select ground points, i.e. deriving the digital terrain model (DTM). The definition of the accurate DTM is essential in case of archaeological and military historical studies. The identification of the relatively small offsets is the key task during the analysis of microrelief, thus as dense point cloud should be used as possible. There are various known processes to select the ground points; the most frequently used algorithms are the weighting based on the relative vertical offsets, and the selection depending on the slope or curvature. We have to mention that in most cases the software work in "black box" mode, so the users only have options to modify a few parameters or define typical land cover options to achieve the best result. Numerous interpolation methods can be applied in creating the elevation model, resulting barely different models. Our experiences have shown, that kriging produced the best results compared with the other methods. The offsets in the microrelief - which have the most important role in the military object reconstruction - appeared the most significant way, and provided the sharpest contrast on this terrain model. Just like the interpolation methods, the various edge detection algorithms have a highlighted role in the military objects reconstruction. Applying these algorithms enables to enhance the accuracy and reliability of the object detection, measure the typical sizes and support the identification. The well-known convolution filters calculate and approximate the direction and the value of the first (Roberts, Sobel) and the second (Laplace) gradients. Usually it is recommended to apply pre- or postprocessing along with these algorithms. For example, smoothing filter can be useful before the edge detection, but we have to apply it carefully because it can erase the important small vertical differences from the data, which are necessary in most reconstruction cases. On the other hand the postprocessing of the filtered data (e.g. thresholding, edge thinning) can significantly improve the interpretation. 
The Figure 2. below represents the results of the fire trench (arrows) detections using different filters (Stal C. et al, 2010).

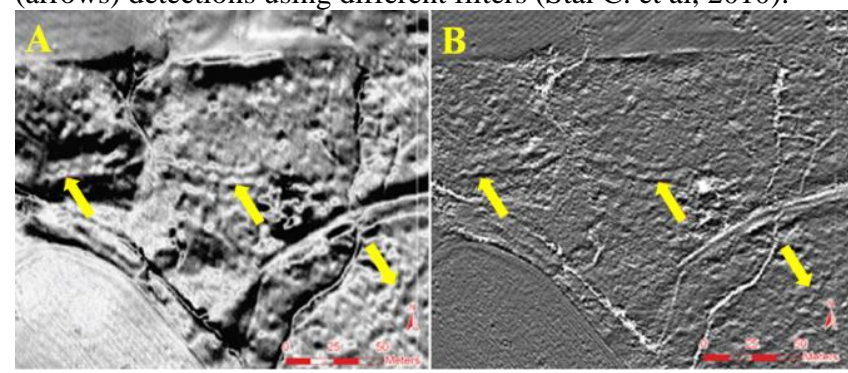

Figure 2. Fire trench detection with Sobel (A) and Laplace (B) filtering

Beside the filters and edge detectors, there are simple visualization and analysis methods that are also able to simplify our task. GIS and CAD software have the ability to create cross and longitudinal sections, extrude the height values or vary the illumination direction. These techniques can facilitate detection, identification, measurement and representation of military objects. Applying the appropriate parameters, the visualization of the point cloud can be more plastic and the important height differences can be highlighted. The classification, the point selection and representation of the LiDAR point clouds can be achieved using special software, but the latest GIS software applications are also able to manage these data. Applying geoinformatics has numerous advantages in reconstruction process:

managing information from different sources in a unified geometric system generating digital terrain model interpolation methods

database connection

spatial queries, analysis

2 and 3 dimensional animation

So, it seems useful to integrate LiDAR data in GIS, because it provides a unified framework for our military historical or archaeological reconstruction. This database can support further services such as digital register or catalogue.

As a consequence, we can declare that the LiDAR point clouds can efficiently support the object reconstruction in various archaeological and military historical periods and events, or even in reconnaissance of potential research areas, called archaeological predictive modeling. To achieve the best result, a thorough selection of processing and representation method is needed. Besides, the fine definition of the data acquisition's parameters (if possible) have also a great influence on the result's quality. The specification of the procedures is as follows:

Reconnaissance according to the land cover:

Open area:

Covered area:

microrelief investigation

evaluation intensity values

- preferably naked period selection

remove vegetation

microrelief investigation

Detection, location:

the densest point cloud

most efficient interpolation

most efficient edge detection

Representation (adequate and aesthetic):

direction of illumination

extrusion the height values

\section{MILITARY HISTORICAL RECONSTRUCTION IN HUNGARIAN SAMPLE AREAS}

\subsection{GIS reconstruction of a South Defense System (SDS) part}

This example is the investigation of a typical part of the SDS near Sátorhely and Majs settlements. The data is from the Janus Pannonius Museum (Pécs). First, we carried out a traditional military historical reconstruction based on conventional data sources (images, maps), then applied LiDAR processing where data was available. All the available maps, aerial images and satellite images were transformed into the Hungarian EOV (Unified National Projection) coordinate system. During the transformation we had to consider that the aerial and satellite images were not orthorectified; both were distorted. There were a few meters of inaccuracy, but according to the reconstruction's demands, it was acceptable.

The first part of a complete military historical reconstruction is the environmental investigation of the area of that period. The environment always has a great influence on the type, position and size of the military defensive system. The environmental reconstruction has two main steps. The past conditions can be derived from the recent state of environment, from maps and aerial photographs (Figure 3.). The map objects were topologically corrected in GIS.

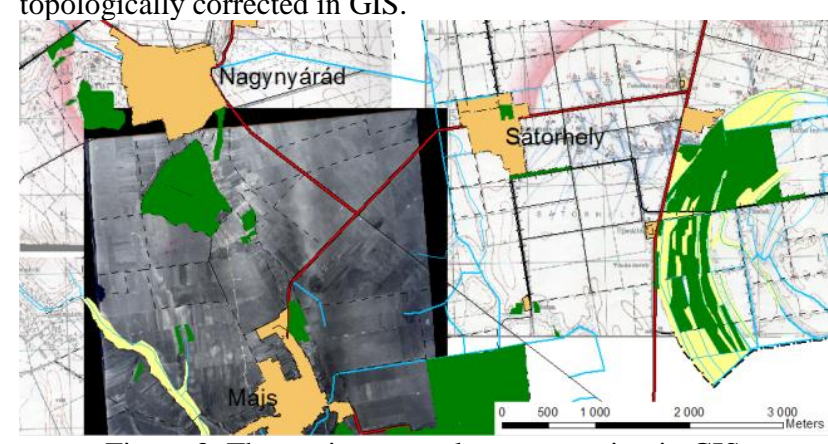

Figure 3. The environmental reconstruction in GIS

Major part of the environmental reconstruction is processing height data. Both topographic maps (contour lines) and LiDAR measurements can be the sources of elevation data. GIS also enables 3D modeling. Unfortunately in our study no laser scanned point cloud was available from the whole investigated area, so we also made a 3D model from the digitized contour lines (Figure 4.). The defending capability of the defensive fortifications is mainly based on its location, depth and defence activity. As it is clearly visible in the investigated part of the SDS, the system was built to effectively stop and repulse the enemy with artillery, tanks and other engineering equipment, together with utilization of the terrain characteristics. The bases of the defence are the connected strongholds with horizontally and vertically unified fire- and obstacle-system (Juhász A. et al, 2015.)

In the following, we review the typical defensive objects and their major characteristics, which can be detected and identified. Fire trench: 0,6-1 meter wide and 1-1,5 meter deep infantry dugout. Based on their typical shape and tracing, these trenches are relatively easy to be identified on archive photographs and in LiDAR data, if not located in an agricultural area.

Anti-tank trench: 8-10 meters wide, 4-6 meters deep trench. Usually these are tens or even hundreds of kilometers long. Also they have a typical shape with linear parts and relatively hard breakpoints. All of the data sources suitable to identify these trenches, even in buried statement. 
Various placements, bunkers: Built in open or covered form alone or integrated in a defensive system. Because of their small (typically few meters in diameter) size, we can manage these objects as points in our investigations. There is only a minor chance to detect these objects today.

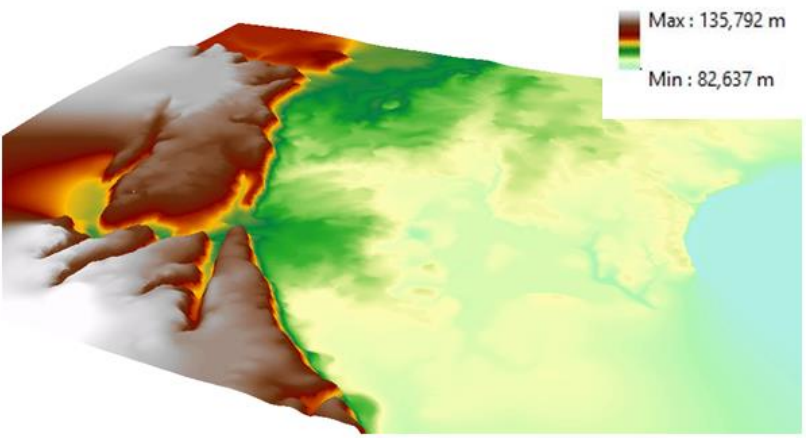

Figure 4 . The digital terrain model of the investigated area

After the environmental reconstruction the next step was the investigation of the military objects. First, we did the traditional way of object reconstruction, using the archive maps and aerial photographs (Figure 5.), then the LiDAR data were integrated into the GIS database.

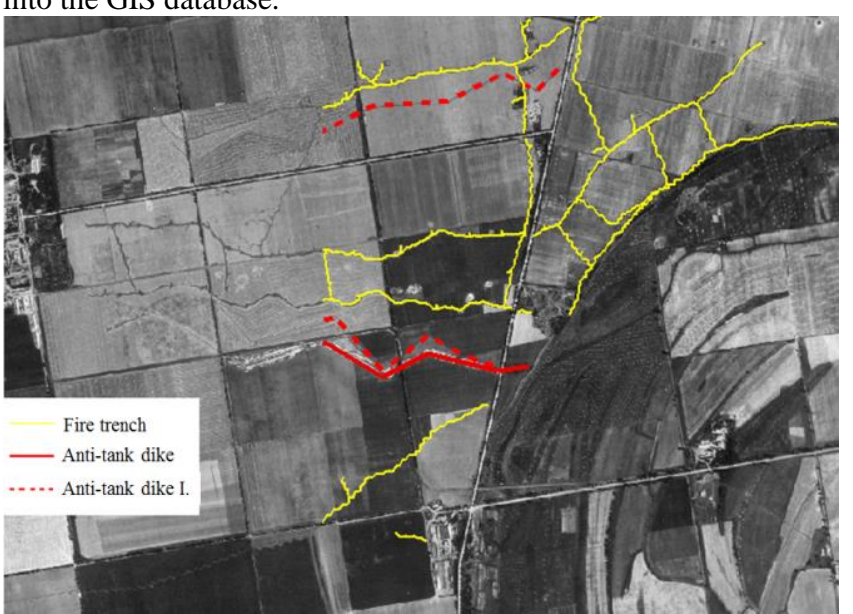

Figure 5. Object reconstruction on archive aerial photographs

Because of the area's current land use (agricultural production) there was no chance to reconstruct fire trenches from the point cloud. However, the signs of the anti-tank trenches were exactly identifiable. During the point cloud processing we investigated different interpolation and edge detection methods to locate the buried objects. The best results (Figure 6.) were achieved by the application of Laplace filtering and kriging and Local Relief Model (Novák D., 2014.). In addition, after the localization, we could measure the typical sizes of the buried trenches by creating detailed profiles and clipping certain parts of the point cloud. As it shown in Figure 7., today, after decades of agriculture, the anti-tank trenches can be identified as a 20-30 cm deep nooks.

After the environmental and military object reconstruction, utilizing the possibilities of the GIS, we carried out typical spatial analysis. We investigated the potential enemy attack directions according to the area's viability (concern to heavy vehicles) by creating slope map and considering streams and wetlands. Than we compared the results with the structure of the defence system. Furthermore, we created the viewshed maps of the commander's observer points, to get more complex overview about the defence system structure.

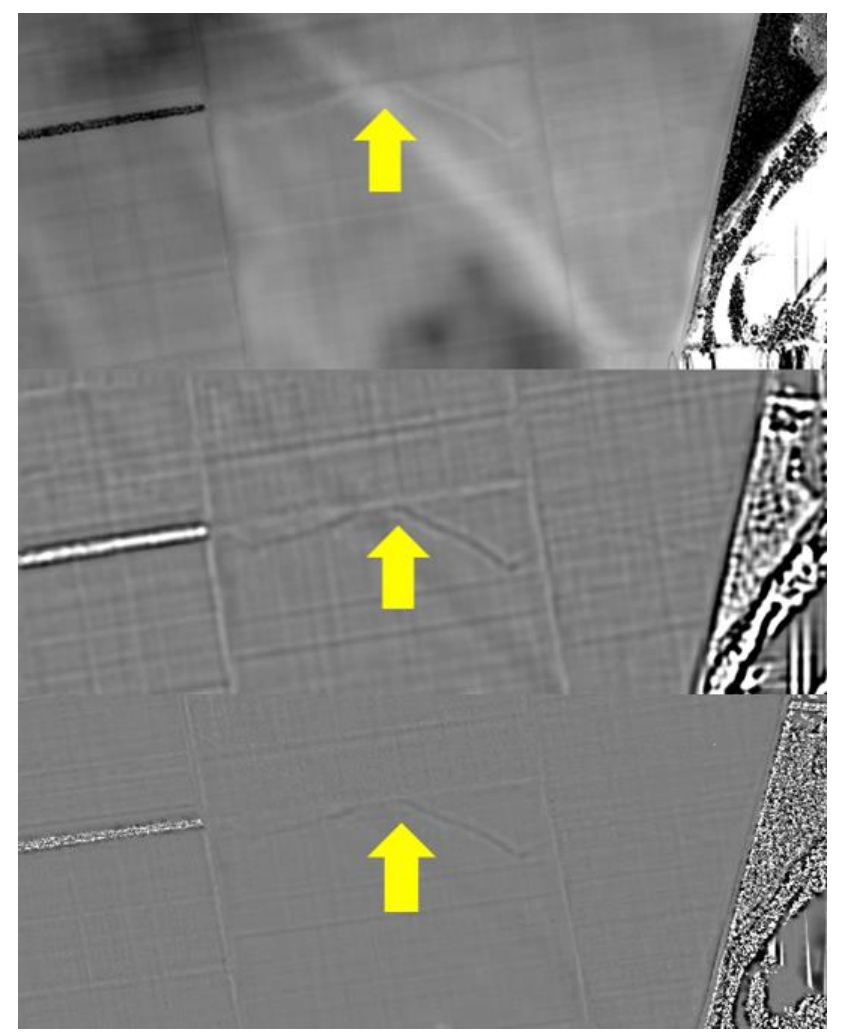

Figure 6. Anti-tank trench identification with Kriging (top), using Laplace filter (middle) and Local Relief Model (bottom)

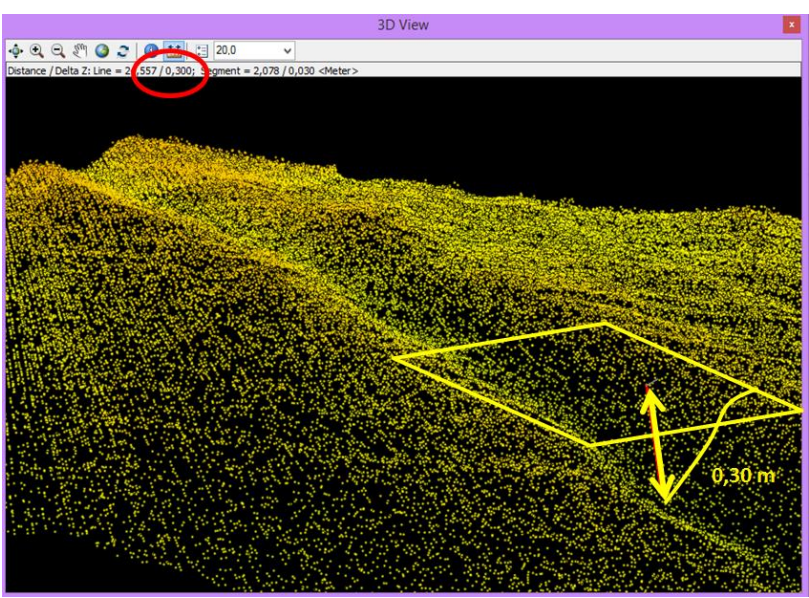

Figure 7. Anti-tank trench in the point cloud

\subsection{Fire trenches in Bükk National Park}

The next sample area - from where LiDAR data were available is situated near Kisgyőr settlement. The data were obtained as part of a cooperation with the Directorate of Bükk National Park. Theoretically a World War II. defence line, called "Karola line" located somewhere in this area, but there is no information about it, because all the documents were perished in the war. In addition, after the war, in the 1950's there was an artillery and infantry shooting-range near the village, so there is a chance of fusion of different objects from different periods. However, our most important purpose was investigating how the old buried fire trenches appear in the point cloud; and how the vegetation influences the identification of fire trenches. Contrary to the first example, so dense vegetation cover (trees, bushes, high grass) was present on significant part of the researched area that the field measurement was nearly impossible. The part of the 
original point cloud and a typical profile are shown in Figure 8. The dense of this point cloud was quite large: approximately 320.000 points in $9600 \mathrm{~m}^{2}$ area, and after the separation (lasground software) of ground points 180.000 points left. The trench is relatively well identifiable in the profile, because its depth is $50-60 \mathrm{~cm}$. Based on this depth size it was a reasonable expectation to reliably identify the trenches after the vegetation removal. Accordingly, it was easy to find the fire trenches with the use of the ground points. (Figure 9.) Only the rain-washes caused some uncertainty in this area. We have to note that in many cases during the wars the defending forces used the rainwashes as trenches, by widening and deepening them. The identification of this type of trench is harder than the traditional ones.
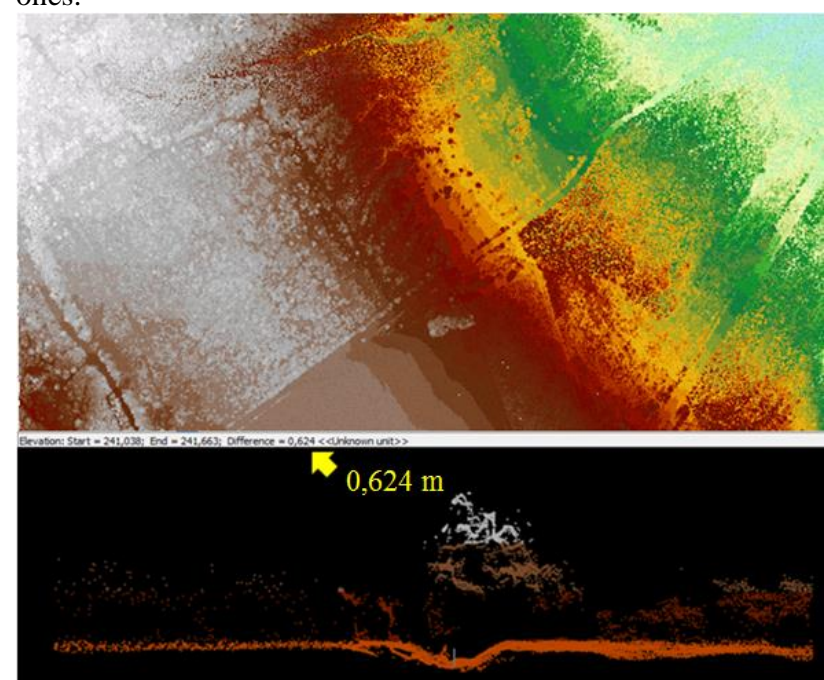

Figure 8 . The original point cloud (top) and a typical profile (down) in Bükk National Park area
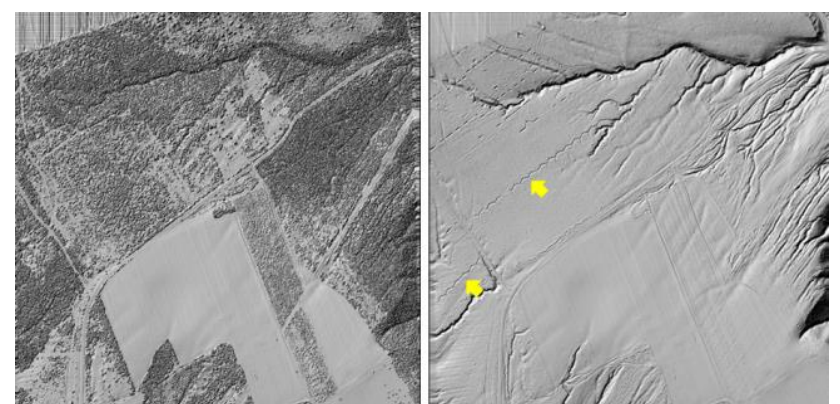

Figure 9. The Digital Surface Model (left) and the Digital Elevation Model (right) with the trenches (arrows) in Bükk National Park area

To control the LiDAR data quality and to check the condition of trenches, we also performed field measurements. We used GNSS RTK receiver. 150 points were measured along the longest trench. The $10^{\text {th }}$ figure shows the value and the deviation of 3D differences between the GNSS points and the DTM generated from LiDAR data. The mean difference was $\sim 7$ $\mathrm{cm}$ and the standard deviation was $\sim 12 \mathrm{~cm}$. Both values are within the margin of measurement error.

\section{CONCLUSIONS}

Based on our results we summarize the advantages of applying LiDAR data in modern age archaeological and military historical reconstructions. Firstly the point clouds can be applied efficiently in digital terrain modelling during the environmental reconstruction process.

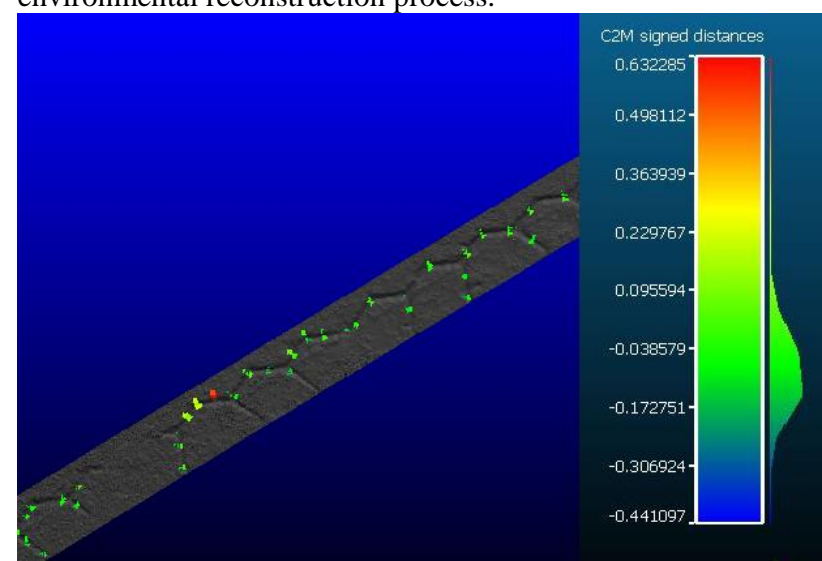

Figure 10. The value and the deviation of 3D differences between the GNSS points and the DTM generated from LiDAR data

The obvious benefits of the technology compared to other traditional data sources are as follows:

$$
\begin{aligned}
& \text { direct 3D output } \\
& \text { homogeneous point distribution } \\
& \text { high accuracy and resolution } \\
& \text { micro relief analysis } \\
& \text { fast process (Rapid DEM) }
\end{aligned}
$$

Secondly, as a part of the military object reconstruction, the buried anti-tank trenches, or even in fortunate cases the fire trenches and the positions are well identifiable in LiDAR data. If the exact trench location is not possible, there is still an opportunity to define potential research areas, where field measurements can be carried out. All of these options are valid in case of vegetation covered areas. The relevant information basically comes from the DEM and from the derived profiles of certain areas. In addition, the recorded intensity values (if available) carry more information about the terrain. It is also important that we don't need specific LiDAR scanning for the object reconstruction; point clouds acquired for any purposes are suitable.

Finally, we define the main steps of LiDAR data process in practice:

$$
\begin{aligned}
& \text { generating manageable amount of data (clip, } \\
& \text { resampling) } \\
& \text { selecting ground points } \\
& \text { classification } \\
& \text { DEM creation } \\
& \text { visualization } \\
& \text { GIS analysis } \\
& \text { archaeological and military historical reconstruction }
\end{aligned}
$$

Our investigation proved that this process is appropriate to integrate laser scanned data into GIS databases, regardless of the investigated archaeological and military historical periods.

\section{REFERENCES}

Bertók G., Gáti Cs, 2014. Régi idők - új módszerek, Archaeolingua, Budapest-Pécs

Novák D., 2014. Local Relief Model (LRM) Toolbox for ArcGIS (UPDATE 2014-10-7), Institute of Archaeology, Czech Academy of Science, Prague, https://www.academia.edu 
/5618967/Local_Relief_Model_LRM_Toolbox_for_ArcGIS_U PDATE_2014-10-7_

Draganits E., Doneus M., Gansum T., Gustavsen L., Nau E., Tonning C., Trinks I., Neubauer W., 2015. The late Nordic Iron Age and Viking Age royal burial site of Borre in Norway: ALSand GPR-based landscape reconstruction and harbour location at an uplifting coastal area. Quaternary International, Vol.367, pp. $96-110$

Evans D-H., Flecher R-J., Pottier C., Chevance J-B., Soutif D., Tan B-S., Im S., Ea D., Tin T., Kim S., Cromarty C., De Greef S., Hanus K., Bâty P., Kuszinger R., Shimoda I., Boornazian G., 2013 Uncovering Archaeological Landscapes at Angkor Using LiDAR In: Proceedings of the National Academy of Sciences of the United States of America 110

Gáti Cs., 2014. A Pécs melletti Jakabhegy őskori földvár LiDAR adatainak régészeti célú kiértékelése és térinformatikai integrálása, Diplomawork

John J., Chvojka O., 2012. Airborne laser scanning (ALS) as a tool for mapping of burial mounds in the area of Hemera forest
(Czech Republic), "Survey in archaeology, often a neglected science", Archaeological Debates, N.2/2012, pp. 187-197

Juhász A., 2007 A special GIS application. Military historical reconstruction. Periodica Polyitechnica 51. 1. pp. 25-31

Juhász A., Neuberger H., 2015. Detecting military historical objects by LiDAR data. Academic and Applied Research in Military Science (AARMS), Vol. 14, No. 2 pp. 219-236

Lovas T., Berényi A., Barsi Á., 2012. Lézerszkennelés, TERC, Budapest

Stal C., Bourgeois J., De Maeyer P., De Mulder G., De Wulf A., Goossens R., Nuttens T., Stichelbaut B., 2010. Kemmelberg (Belgium) case study: comparion of DTM analysis methods for the detection of relicts from the First World War, Remote Sensing for Science, Education, and Natural and Cultural Heritage, EARSeL, pp. 65-71

Vosselmann G., Maas H-G. (Eds), 2010. Airborne and Terrestrial Laser Scanning, CRC Press 